\title{
A Study of $\mathrm{K} / \mathrm{Ti}$-co-doped $\mathrm{NaAlH}_{4}$ on Thermodynamic Tailoring, Surplus Hydrogen Amount and Metal Hydride Molar Volume
}

\author{
Roland H. Pawelke
}

\begin{abstract}
A remarkable finding of metal hydride hydrogen storage is that substituting $4 \mathrm{~mol} \%$ sodium by potassium in $4 \mathrm{~mol} \%$ Tidoped $\mathrm{NaAlH}_{4}$ raises the reversible hydrogen storage capacity from $3.3 \% \mathrm{w} / \mathrm{w} \mathrm{H}$ to $4.7 \% \mathrm{w} / \mathrm{w} \mathrm{H}$. This increase by $42 \%$ is concomitant with a slightly lower desorption enthalpy: intriguingly enough, it is substantially more hydrogen capacity at slightly less desorption enthalpy. The general solution to that puzzle has been already derived from a gas phase point of view, taking advantage of the equilibrium nature of the matter, which thus comes in terms of an ideal gas chemical potential. However, it is also interesting to investigate for the flipside effect in the sorbent phase, affecting molar volume. This paper elucidates by the example of $\mathrm{K} / \mathrm{Ti}$-co-doped $\mathrm{NaAlH}_{4}$ the relation of doping modifications to surplus hydrogen amount and hydride molar volume, defining the term "reaction pathway" in this context, yielding the according figures.
\end{abstract}

\section{Introduction}

At times, there are reactions which epitomize virtually a whole field of chemistry as embracing most or all the concepts vital to it: an example for fundamental organic chemistry is the rearrangement of furfuryl alcohol to 4-hydroxycyclopent-2-en-1-one under acidic aqueous conditions. ${ }^{1}$ Ti-doped $\mathrm{NaAlH}_{4}$ assumes a likewise role in metal hydride chemistry, ${ }^{2-5}$ especially if co-doped with potassium: ${ }^{6,7}$ WANG et al found in 2005 that substituting a mere $4 \mathrm{~mol} \% \mathrm{Na}$ by $\mathrm{K}$ in $\mathrm{Ti}^{-\mathrm{NaAlH}_{4}}$ raises the reversible hydrogen storage capacity from common $3.3 \% \mathrm{w} / \mathrm{w} \mathrm{H}$ to $4.7 \% \mathrm{w} / \mathrm{w} \mathrm{H}^{6}{ }^{6}$ That is one outstanding finding about $\mathrm{NaAlH}_{4}$, maybe only second to the discovery of Ti-catalysis itself. ${ }^{2}$ Oddly enough, that massive increase in hydrogen storage capacity by $42 \%$ leaves the van't Hoff reaction parameters virtually unscathed; actually the global desorption enthalpy is with $38.90 \mathrm{~kJ}\left(\mathrm{~mol} \mathrm{H}_{2}\right)^{-1}$

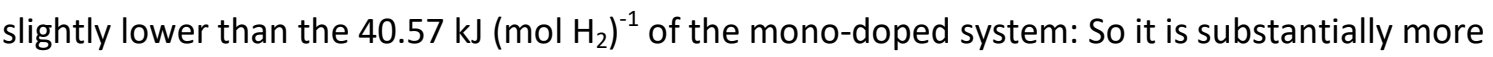
hydrogen capacity at slightly less desorption enthalpy? That tells something of significance although nobody except the author seemingly ever attempted to make global sense out of that: the point about the equilibrium nature of reversible chemical hydrogen storage and doping effects has already been made from a gas phase perspective. ${ }^{8,9}$ While that general solution comes in terms of hydrogen gas chemical potential, ${ }^{8,9}$ i.e. temperature and pressure, switching perspective from gas to sorbent phase thermodynamics entails a change in metrics towards sorbent phase molar volume: That way the flipside manifestation of a chemical potential change in the gas phase shows in the equilibrium system. This principle enables the assessment of metal volume expansion upon hydride formation on the sole basis of van't Hoff data as well as identifying the pressure requirements to the formation of a distinct hydride phase.$^{10}$ However, the principle reaches further as it must ultimately allow insight into how doping respective thermodynamic tailoring effects materialize in the sorbent phase: This paper examines that relation between dopant, sorbent phase molar volume and surplus hydrogen amount by the example of K/Ti-co-doped $\mathrm{NaAlH}_{4}$. 


\section{Methodical Approach}

A work primarily concerned with metal volume expansion upon hydride formation shows the conditional threshold pressure to hydride phase formation being given by the relation of equation 1 , derived by means of the ideal gas law for the exemplary problem of $\left[\mathrm{AlH}_{4}\right]$-formation in $\mathrm{Ti}^{-} \mathrm{NaAlH}_{4}{ }^{10}$

$p>\frac{4005}{\forall_{\mathrm{m}, \mathrm{NaAlH} 4}} \operatorname{bar} \mathrm{cm}^{3}\left(\mathrm{~mol} \mathrm{H}_{2}\right)^{-1}=\frac{\Delta H}{\forall_{\mathrm{m}, \mathrm{NaAlH} 4}} \quad \mid \quad(\Delta H>0)$

Joule is expressed as bar $\mathrm{cm}^{3}$, the reaction enthalpy $\Delta H$ represents the $40050 \mathrm{~J}\left(\mathrm{~mol} \mathrm{H}_{2}\right)^{-1}$ of BOGDANOVIĆ et al. ${ }^{3} \forall_{\mathrm{m} \text {, NaAlH4 }}$ is the hydrogen equivalent molar volume of the $\mathrm{NaAlH}_{4}$ phase: It is generally obtained by adjusting the geometric mean molar volume of all hydride phases (due to the transient nature of that quantity) to the stoichiometric weight of a distinct hydride phase in the reaction equation in relation to the hydrogen equivalents (equations $2 \mathrm{a}$ to $2 \mathrm{c}$ ). ${ }^{10}$

$$
\begin{aligned}
& \mathrm{NaAlH}_{4} \rightleftharpoons 1 / 3 \mathrm{Na}_{3} \mathrm{AlH}_{6}+2 / 3 \mathrm{Al}+\mathrm{H}_{2} \rightleftharpoons \mathrm{NaH}+\mathrm{Al}+0.5 \mathrm{H}_{2} \\
& V_{\mathrm{m}, \mathrm{NaAlH} 4}=43 \mathrm{~cm}^{3} \mathrm{~mol}^{-1} \quad V_{\mathrm{m}, \mathrm{Na} 3 \mathrm{AlH}}=70 \mathrm{~cm}^{3} \mathrm{~mol}^{-1} \quad \nabla_{\mathrm{m}, \mathrm{NaAlH}}=\sqrt[3]{43 \cdot 43 \cdot 70} \mathrm{~cm}^{3} \mathrm{~mol}^{-1} \approx 51 \mathrm{~cm}^{3} \mathrm{~mol}^{-1}
\end{aligned}
$$

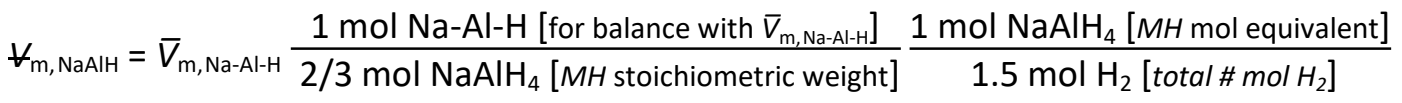

$$
\begin{aligned}
& =51 \mathrm{~cm}^{3}\left(\mathrm{~mol} \mathrm{H}_{2}\right)^{-1} \\
& \forall_{\mathrm{m}, \mathrm{Na} \text { AAlH } 6}=\nabla_{\mathrm{m}, \mathrm{Na}-\mathrm{Al}-\mathrm{H}} \frac{1 \mathrm{~mol} \mathrm{Na}-\mathrm{Al}-\mathrm{H}}{1 / 3 \mathrm{~mol} \mathrm{Na}_{3} \mathrm{AlH}_{6}} \frac{1 \mathrm{~mol} \mathrm{Na}_{3} \mathrm{AlH}_{6}}{1.5 \mathrm{~mol} \mathrm{H}_{2}} \\
& =102 \mathrm{~cm}^{3}\left(\mathrm{~mol} \mathrm{H}_{2}\right)^{-1}
\end{aligned}
$$

On that basis it can be investigated how doping respective thermodynamic tailoring effects materialize in metal hydrides.

\section{Results}

It is reasonable to relate the effects caused by $\mathrm{KH}$-doping with the next stable mixed alanate $\mathrm{K}_{2} \mathrm{NaAlH}_{6}{ }^{9}{ }^{9}$ as $\mathrm{KNa}_{2} \mathrm{AlH}_{6}$ is instable. ${ }^{11,12}$ Its density is calculated by the entropy method, ${ }^{10}$ on basis of the data of $\mathrm{S} \varnothing \mathrm{RBY}$ et $a l^{13}$ as shown in equations $3 \mathrm{a}$ to $3 \mathrm{c}$; the required $\mathrm{NaH}$ and $\mathrm{Al}$ densities base on Römpp's chemistry lexicon, ${ }^{14,15}$ those of $\mathrm{KH}$ on data provided by American Elements.

$$
\begin{aligned}
& \mathrm{K}_{2} \mathrm{NaAlH}_{6} \rightleftharpoons 2 \mathrm{KH}+\mathrm{NaH}+\mathrm{Al}+1.5 \mathrm{H}_{2} \\
& \Delta \mathrm{S}=-15.04 \mathrm{bar} \mathrm{cm}^{3}\left(\mathrm{~mol} \mathrm{H}_{2}\right)^{-1} \mathrm{~K}^{-1} \\
& x_{\mathrm{K} 2 \mathrm{NaAlH} 6}=-\frac{\mathrm{T}^{\circ} \Delta S}{\mathrm{p}^{\circ} \mathrm{V}_{\mathrm{m}}^{\circ}}=\Delta V_{\%}=0.1809 \\
& \rho_{M}=\frac{\rho_{\mathrm{NaH}}+2 \rho_{\mathrm{KH}}+\rho_{\mathrm{Al}}}{4}=1.76 \mathrm{~g} \mathrm{~cm}^{-1} \\
& \rho_{\mathrm{KH}}=1.470 \mathrm{~g} \mathrm{~cm}^{-3} \quad \rho_{\mathrm{NaH}}=1.396 \mathrm{~g} \mathrm{~cm}^{-3} \quad \rho_{\mathrm{Al}}=2.702 \mathrm{~g} \mathrm{~cm}^{-3}
\end{aligned}
$$


Based on this result, the crystal density and molar volume of $\mathrm{K}_{2} \mathrm{NaAlH}_{6}$ is calculated according to equation $4 a$ and $4 b$.

$$
\begin{aligned}
& \frac{\rho_{\mathrm{K} 2 \mathrm{NaAlH}}}{*}=(-1)(0.1809-1) \rho_{M}=1.44 \mathrm{~g} \mathrm{~cm}^{-3} \\
& M W_{\text {K2NaAlH6 }}=134.22 \mathrm{~g} \mathrm{~mol}^{-1} \\
& V_{\mathrm{m}, \mathrm{K} 2 \mathrm{NaAlH} 6}=93.21 \mathrm{~cm}^{3} \mathrm{~mol}^{-1} \approx 93 \mathrm{~cm}^{3} \mathrm{~mol}^{-1}
\end{aligned}
$$

The doping effect in the sorbent is indirectly determined via gas phase thermodynamics: starting from a gas volume at IUPAC standard temperature and pressure (STP), introducing the sorbent phase entails hydrogen absorption respective hydride formation. This causes a pressure drop from $p^{\circ}$ to $p_{\mathrm{H} 2}$ and the chemical potential of the gas phase is excursed from $\mu^{\circ}$ by $\mu_{\mathrm{H} 2}=-\Delta H$ accordingly $(\Delta H>0) ;{ }^{9}$ the extent of this excursion is a measure for the hydrogen capacity. Re-establishing a pressure of 1 bar above the sorbent requires the temperature $T_{1 \mathrm{bar}}=\Delta H / \Delta S$. Equation 5 depicts the absorption process in terms of gas phase chemical potential with the $R T$-term expressed as $p^{\circ} \Delta V_{m}$.

$\mu^{\circ}-\mu_{\mathrm{H} 2}=p^{\circ}\left(V_{m}^{\circ}-V_{m, H 2}\right) \ln \left(\frac{p^{\circ}}{p_{\mathrm{H} 2}}\right)$

Equation 5 refers to the single sorbent; the difference between two sorbents is shown in equation 6 : the initial Ti-NaAlH ${ }_{4}$ system is tagged $\mu_{1}$, the $\mathrm{K} / \mathrm{Ti}$-co-doped system $\mu_{2}$, accordingly.

$$
\begin{aligned}
& \left(\mu^{\circ}-\mu_{1}\right)-\left(\mu^{\circ}-\mu_{2}\right)=\mathrm{p}^{\circ}\left(\left(\mathrm{V}_{\mathrm{m}}{ }^{\circ}-V_{\mathrm{m}, 1}\right)-\left(\mathrm{V}_{\mathrm{m}}^{\circ}-V_{\mathrm{m}, 2}\right)\right) \ln \left(\frac{p_{2}}{p_{1}}\right) \\
\Rightarrow \quad & \mu_{2}-\mu_{1}=\mathrm{p}^{\circ}\left(V_{\mathrm{m}, 2}-V_{\mathrm{m}, 1}\right) \ln \left(\frac{p_{2}}{p_{1}}\right)
\end{aligned}
$$

Standard pressure is drawn into the In-term and equation 6 is e-functioned, leading to equation 7.

$\left(\frac{p_{2}}{p_{1}}\right)^{p^{\circ}} \exp \left(V_{m, 2}-V_{m, 1}\right)=\exp \left(\mu_{2}-\mu_{1}\right)$

In the standard state applies $p_{2}=p_{1}=p^{\circ}$ from which follows that the difference of the chemical potential excursions from $\mu^{\circ}$ featured by each hydrogen sorbent, $\mu_{2}-\mu_{1}$, is equal to the difference of the respective ensuing gas phase molar volumes: that can be alternately expressed in relative terms to $\mu_{1}$ respective $V_{\mathrm{m}, 1}$, as equation 8 shows.

$\exp \left(V_{m, 2}-V_{m, 1}\right)=\exp \left(\mu_{2}-\mu_{1}\right) \quad \Rightarrow \quad \exp \left(\frac{V_{m, 2}-V_{m, 1}}{V_{m, 1}}\right)=\exp \left(\frac{\mu_{2}-\mu_{1}}{\mu_{1}}\right)$

The molar gas phase volumes in equation 8 translate via the hydrogen equivalent metal hydride molar volumes $\forall_{m}$ to the respective average hydride phase molar volumes $\nabla_{m}$ (equation $2 \mathrm{~b}$ ). The 
surplus hydrogen amount of the co-doped system relative to the initial system is obtained by taking the derivative of equation 8 with reference to the molar volume exponent. Because the derivative of $\mathrm{e}^{x}$ with reference to $x$ is $\mathrm{e}^{x}$, the result can be approximated by a Maclaurin series which stops after the first order (linear) coefficient: That is because the ideal gas reversible hydrogen capacity scales linearly in increments of $\mu_{1 \%}{ }^{\circ}=-12033 \mathrm{~J}\left(\mathrm{~mol} \mathrm{H}_{2}\right)^{-1}$ per $[1 \% \mathrm{w} / \mathrm{w} \mathrm{H}]$ storage capacity in relation to the negative desorption (thus absorption) enthalpy $-\Delta H$ of a reaction pathway $(\Delta H>0) .{ }^{9}$ Equation 9 shows the according calculation of the relative difference in hydrogen capacity between both reaction pathways: the mean hydride phase molar volume of the potassium co-doped $\mathrm{Ti}^{-\mathrm{NaAlH}_{4}}$ is tagged $\nabla_{\mathrm{m}, \mathrm{Na} / \mathrm{K}-\mathrm{Al}-\mathrm{H},}$ those of the solely Ti-doped $\mathrm{NaAlH}_{4}$ is termed $\nabla_{\mathrm{m}, \mathrm{Na}-\mathrm{Al}-\mathrm{H}}$.

$(\mathrm{NaH})_{0.96}+(\mathrm{KH})_{0.04}+\mathrm{Al} \longrightarrow 0.02 \mathrm{~K}_{2} \mathrm{NaAlH}_{6}+0.94 \mathrm{NaAlH}_{4}+0.02 \mathrm{Al}$

$0.02 \mathrm{~K}_{2} \mathrm{NaAlH}_{6}+0.94 \mathrm{NaAlH}_{4}+0.02 \mathrm{Al} \rightleftharpoons 0.02 \mathrm{~K}_{2} \mathrm{NaAlH}_{6}+0.94\left(\mathrm{NaH}+\mathrm{Al}+1.5 \mathrm{H}_{2}\right)+0.02 \mathrm{Al}$

$\bar{V}_{\mathrm{m}, \mathrm{Na} / \mathrm{K}-\mathrm{Al}-\mathrm{H}}=\sqrt[4]{(0.94)(43 \cdot 43 \cdot 70)(0.02 \cdot 93)} \mathrm{cm}^{3} \mathrm{~mol}^{-1}=21.81 \mathrm{~cm}^{3} \mathrm{~mol}^{-1} \approx 22 \mathrm{~cm}^{3} \mathrm{~mol}^{-1}$

$\nabla_{\mathrm{m}, \mathrm{Na}-\mathrm{Al}-\mathrm{H}}=\sqrt[3]{43 \cdot 43 \cdot 70} \mathrm{~cm}^{3} \mathrm{~mol}^{-1} \approx 51 \mathrm{~cm}^{3} \mathrm{~mol}^{-1}$

$\frac{d\left(\exp \left(\frac{\bar{V}_{m, \text { Na} / \mathrm{K}-\mathrm{Al}-\mathrm{H}}}{\bar{V}_{\mathrm{m}, \mathrm{Na}-\mathrm{Al}-\mathrm{H}}}-1\right)\right)}{\mathrm{d}\left(\frac{\bar{V}_{\mathrm{m}, \mathrm{Na} / \mathrm{K} \text {-Al-H }}}{\bar{V}_{\mathrm{m}, \mathrm{Na}-\mathrm{Al}-\mathrm{H}}}-1\right)}=\exp \left(\frac{\bar{V}_{\mathrm{m}, \mathrm{Na} / \mathrm{K}-\mathrm{Al}-\mathrm{H}}}{\bar{V}_{\mathrm{m}, \mathrm{Na}-\mathrm{Al}-\mathrm{H}}}-1\right) \approx 1+\frac{\bar{V}_{\mathrm{m}, \mathrm{Na} / \mathrm{K} \text {-Al-H }}}{\bar{V}_{\mathrm{m}, \mathrm{Na}-\mathrm{Al}-\mathrm{H}}}-1=+0.43$

Equation 9 tells that $43 \%$ more hydrogen capacity can be expected from the co-doping process with potassium and multiplying the $3.3 \% \mathrm{w} / \mathrm{w} \mathrm{H}$ of the solely Ti-doped $\mathrm{NaAlH}_{4}$ system with 1.43 yields a hydrogen storage capacity of $4.72 \% \mathrm{w} / \mathrm{w} \mathrm{H}$ for the $\mathrm{K}$-co-doped Ti-NaAlH $\mathrm{H}_{4}$ system. WANG et al report $4.7 \% \mathrm{w} / \mathrm{w} \mathrm{H}$ so already this deviation of $4.3 \%$ is below the resolution of that figure; correcting the outcome by the factor 0.99 (surplus aluminium) yields in fine agreement $1.4157 \approx 1.42$ as result.

\section{Discussion}

Equation 9 shows that the co-doping process creates a new reaction pathway of lower average hydride phase molar volume; however, it is to consider that the new pathway is embedded at dopant concentration into the base equilibrium system and due to the stability of $\mathrm{K}_{2} \mathrm{NaAlH}_{6}$ of 98.2 $\mathrm{kJ}\left(\mathrm{mol} \mathrm{H}_{2}\right)^{-1},{ }^{13}$ it is supposedly effective in the absorption reaction only. Thus it is barely recognizable in the apparent thermodynamic reaction properties. Speaking of reaction pathways, this term lacks proper definition in this context: equation 9 suggests one on basis of the hydrogen equivalent molar volume $\forall_{m}$ of a distinct hydride phase, to which the (doped) reaction sum formula and the stoichiometry-weighted geometric mean metal hydride phase molar volume are vital. Equilibrium interoperability of the newly created phase with the base system is therefore a qualitative requirement to successful doping for higher hydrogen storage capacity. The lower average hydride phase molar volume reflects the increase in specific energy. That principle might be in adjusted form of further avail to understanding the nature of Ti-catalysis in $\mathrm{NaAlH}_{4}$ better, ${ }^{16,17}$ which is however beyond current scope. The $\mathrm{K} / \mathrm{Ti}$-co-doped $\mathrm{NaAlH}_{4}$ system represents a most impressive and instructive example for successful thermodynamic tailoring: it appears strange that the two most recent, quite voluminous alanate reviews do not mention its remarkable features - at all. ${ }^{4,5}$ 
Asking why that might be the case is tempting but would lead the narrative away from its conclusion: This work's findings substantiate once more that a comprehensive, convergent understanding of reversible chemical hydrogen storage requires essentially just the ideal gas law and classic equilibrium thermodynamics, irrespective of whether scope rests on the properties of the gas or the sorbent phase. That may be called either old-fashioned or timeless: in any case, this way of approaching the matter rewards with convergence in outcome and insight without any need to jettison scientific consistency at any level. The difference between this view and the status quo (ante) scientific consensus may be brought to the fore of the mind in contrast to two fairly recent high-profile epitomes of the latter. ${ }^{18,19}$

\section{Conclusions}

The substantial increase in hydrogen storage capacity by $42 \%$ resulting from potassium co-doping of Ti-NaAlH $\mathrm{H}_{4}$ can be traced down to a reaction pathway of lower average hydride phase molar volume, in the event arriving at a general, contextual first-time definition of the term "reaction pathway".

\section{Acknowledgements}

This article originates from work done at FOTEC Forschungs- und Technologietransfer GmbH in Wiener Neustadt, Austria, under European Space Agency grant 4000105330/12/NL/CLP, which is gratefully appreciated.

\section{Conflicts of Interest}

There are no conflicts to declare.

\section{References}

(1) Curran, T. T.; Hay, D. A.; Koegel, C. P.; Evans, J. C. The Preparation of Optically Active 2-Cyclopenten-1,4-Diol Derivatives from Furfuryl Alcohol. Tetrahedron 1997, 53 (6), 1983-2004. https://doi.org/10.1016/S00404020(96)01169-6.

(2) Bogdanović, B.; Schwickardi, M. Ti-Doped Alkali Metal Aluminium Hydrides as Potential Novel Reversible Hydrogen Storage Materials. J. Alloys Compd. 1997, 253-254, 1-9. https://doi.org/10.1016/S0925-8388(96)03049-6.

(3) Bogdanović, B.; Brand, R. A.; Marjanović, A.; Schwickardi, M.; Tölle, J. Metal-Doped Sodium Aluminium Hydrides as Potential New Hydrogen Storage Materials. J. Alloys Compd. 2000, 302 (1-2), 36-58. https://doi.org/10.1016/S0925-8388(99)00663-5.

(4) Milanese, C.; Garroni, S.; Gennari, F.; Marini, A.; Klassen, T.; Dornheim, M.; Pistidda, C. Solid State Hydrogen Storage in Alanates and Alanate-Based Compounds: A Review. Metals 2018, 8 (8), 567. https://doi.org/10.3390/met8080567.

(5) Suárez-Alcántara; Tena-Garcia; Guerrero-Ortiz. Alanates, a Comprehensive Review. Materials 2019, 12 (17), 2724. https://doi.org/10.3390/ma12172724.

(6) Wang, P.; Kang, X.-D.; Cheng, H.-M. KH+Ti Co-Doped NaAlH4 for High-Capacity Hydrogen Storage. J. Appl. Phys. 2005, 98 (7), 074905. https://doi.org/10.1063/1.2084308.

(7) Liu, Y.; Liang, C.; Zhou, H.; Gao, M.; Pan, H.; Wang, Q. A Novel Catalyst Precursor $\mathrm{K}_{2} \mathrm{TiF}_{6}$ with Remarkable Synergetic Effects of K, Ti and F Together on Reversible Hydrogen Storage of $\mathrm{NaAlH}_{4}$. Chem Commun 2011, 47 (6), 1740-1742. https://doi.org/10.1039/C0CC03264F.

(8) Pawelke, R. H. On the Common Ground of Thermodynamics and Kinetics: How to Pin Down Overpotential to Reversible Metal Hydride Formation and the Complete Ideal Gas Theory of Reversible Chemical Hydrogen Storage; preprint; 2021. https://doi.org/10.26434/chemrxiv.13308875.v3.

(9) Pawelke, R. H. The Master Key to the Problem of Reversible Chemical Hydrogen Storage Is $12 \mathrm{KJ}\left(\mathrm{Mol} \mathrm{H}_{2}\right)^{-1}$; preprint; 2021. https://doi.org/10.26434/chemrxiv.6940379.v10. 
(10) Pawelke, R. H. The Thermodynamic Way of Assessing Reversible Metal Hydride Volume Expansion: Getting a Grip on Metal Hydride Formation Overpotential; preprint; 2021. https://doi.org/10.26434/chemrxiv.10316819.v4.

(11) Løvvik, O. M.; Swang, O. Structure and Stability of Possible New Alanates. Europhys. Lett. EPL 2004, 67 (4), 607613. https://doi.org/10.1209/epl/i2004-10105-x.

(12) Graetz, J.; Lee, Y.; Reilly, J. J.; Park, S.; Vogt, T. Structures and Thermodynamics of the Mixed Alkali Alanates. Phys. Rev. B 2005, 71 (18), 184115-184122. https://doi.org/10.1103/PhysRevB.71.184115.

(13) Sørby, M. H.; Brinks, H. W.; Fossdal, A.; Thorshaug, K.; Hauback, B. C. The Crystal Structure and Stability of K2NaAlH6. J. Alloys Compd. 2006, 415 (1-2), 284-287. https://doi.org/10.1016/j.jallcom.2005.08.010.

(14) Sitzmann, H. Natriumhydrid. Thieme Gruppe December 9, 2007.

(15) Vollmer, A.; Habermeyer, M.; RÖMPP-Redaktion; Sitzmann, H.; Schwab, E. Aluminium. Thieme Gruppe May 1, 2019.

(16) Wang, Q.; Chen, Y.; Wu, C.; Tao, M. Catalytic Effect and Reaction Mechanism of Ti Doped in NaAlH4: A Review. Sci. Bull. 2008, 53 (12), 1784-1788. https://doi.org/10.1007/s11434-008-0234-4.

(17) Frankcombe, T. J. Proposed Mechanisms for the Catalytic Activity of Ti in NaAlH 4. Chem. Rev. 2012, 112 (4), $2164-$ 2178. https://doi.org/10.1021/cr2001838.

(18) Morris, L.; Hales, J. J.; Trudeau, M. L.; Georgiev, P.; Embs, J. P.; Eckert, J.; Kaltsoyannis, N.; Antonelli, D. M. A Manganese Hydride Molecular Sieve for Practical Hydrogen Storage under Ambient Conditions. Energy Environ. Sci. 2019, 12 (5), 1580-1591. https://doi.org/10.1039/C8EE02499E.

(19) Yu, S.; Li, S.; Wan, C.; Ju, X. Synergistic Effect of Li-Ti and K-Ti Co-Doping on the Dehydrogenation Properties of $\mathrm{NaAlH}_{4}$ : An Ab Initio Study. RSC Adv. 2016, 6 (92), 89895-89900. https://doi.org/10.1039/C6RA15280E. 